\title{
Late Gadolinium Enhancement for Prediction of Mutation-Positive Hypertrophic Cardiomyopathy on the Basis of Panel-Wide Sequencing
}

\author{
Ryota Teramoto, MD; Noboru Fujino, MD, PhD; Tetsuo Konno, MD, PhD; \\ Akihiro Nomura, MD, PhD; Yoji Nagata, MD; Toyonobu Tsuda, MD, PhD; \\ Hayato Tada, MD, PhD; Kenji Sakata, MD, PhD; Masakazu Yamagishi, MD, PhD; \\ Kenshi Hayashi, MD, PhD; Masa-aki Kawashiri, MD, PhD
}

\begin{abstract}
Background: Cardiac magnetic resonance (CMR) with late gadolinium enhancement (LGE) revealed a substantial variation in the extent of myocardial scarring, a pathological hallmark of hypertrophic cardiomyopathy (HCM). However, few data exist regarding the relationship between the presence of gene mutations and the extent of LGE. Therefore, we aimed to investigate whether variations in the extent of LGE in HCM patients can be explained by the presence or absence of disease-causing mutations.

Methods and Results: We analyzed data from 82 unrelated HCM patients who underwent both LGE-CMR and next-generation sequencing. We identified disease-causing sarcomere gene mutations in 44 cases (54\%). The extent of LGE on CMR was an independent factor for predicting mutation-positive HCM (odds ratio 2.12 [95\% confidence interval 1.51-3.83], $\mathrm{P}<0.01$ ). The area under the curve of \%LGE was greater than that of the conventional Toronto score for predicting the presence of a mutation ( 0.96 vs. $0.69, \mathrm{P}<0.01$ ). Sensitivity, specificity, positive predictive value, and negative predictive value of $\%$ LGE (cutoff $>8.1 \%$ ) were $93.2 \%$, $89.5 \%, 91.1 \%$, and $91.9 \%$, respectively.

Conclusions: The results demonstrated that \%LGE clearly discriminated mutation-positive from mutation-negative HCM in a clinically affected HCM population. HCM with few or no myocardial scars may be genetically different from HCM with a higher incidence of myocardial scars.
\end{abstract}

Key Words: Cardiac magnetic resonance imaging; Fibrosis; Hypertrophic cardiomyopathy

$\mathbf{H}$ ypertrophic cardiomyopathy $(\mathrm{HCM})$ is characterized by unexplained left ventricular hypertrophy $(\mathrm{LVH})$ caused by mutations in genes that encode sarcomere protein. ${ }^{1}$ Myocardial fibrosis is a major histopathologic feature of HCM, which can be classified into either myocardial scar or interstitial fibrosis. ${ }^{2,3}$ Cardiac magnetic resonance imaging (CMR) with late gadolinium enhancement (LGE) imaging has been established as the modality for assessing myocardial scarring in HCM patients. Previous data demonstrated a substantial variation in the extent of myocardial scarring determined by LGE-CMR., ${ }^{4,5}$ Although it has been postulated that myocardial scar may be subsequent to cardiomyocyte death caused by myocardial ischemia and metabolic abnormalities, ${ }^{\mathbf{1}}{ }^{\mathbf{6}}$ other data have indicated that myocardial scarring could be a primary expression of $\mathrm{HCM}^{7}$

The development of genetic testing has enabled the identification of subgroups of HCM based on clinical and genetic information. ${ }^{8}$ Recent data revealed that $40 \%$ of
HCM probands did not have a family history or sarcomere gene mutations, and were classified into a new subgroup, nonfamilial HCM. ${ }^{8}$ Although Ellims et a ${ }^{9}$ showed that the presence of LGE is higher in genotype-positive HCM patients than in patients with genotype-negative HCM, it is unclear whether variations in the extent of LGE in HCM patients can be explained by the presence or absence of disease-causing mutations. Therefore, in this study, we aimed to investigate whether HCM patients with absence or a small extent of LGE constitute a previously unrecognized subgroup of HCM, by using comprehensive genetic testing of all known HCM-related genes by next-generation sequencing (NGS).

\section{Methods}

Study Population and Clinical Evaluation

Clinically affected HCM patients at Kanazawa University Hospital or its affiliate hospitals that registered in our

Received September 22, 2017; revised manuscript received November 29, 2017; accepted December 19, 2017; released online February 3, 2018 Time for primary review: 32 days

Department of Cardiovascular and Internal Medicine, Kanazawa University Graduate School of Medicine, Kanazawa, Japan

Mailing address: Masakazu Yamagishi, MD, PhD, Department of Cardiovascular and Internal Medicine, Kanazawa University Graduate School of Medicine, 13-1 Takara-machi, Kanazawa 920-8641, Japan. E-mail: myamagi@med.kanazawa-u.ac.jp

ISSN-1346-9843 All rights are reserved to the Japanese Circulation Society. For permissions, please e-mail: cj@j-circ.or.jp 

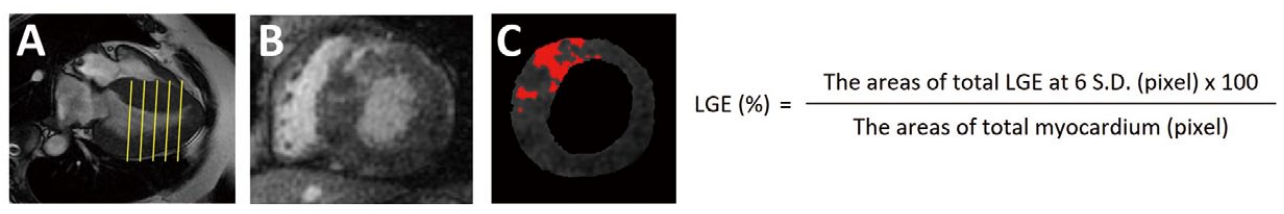

Clinical features
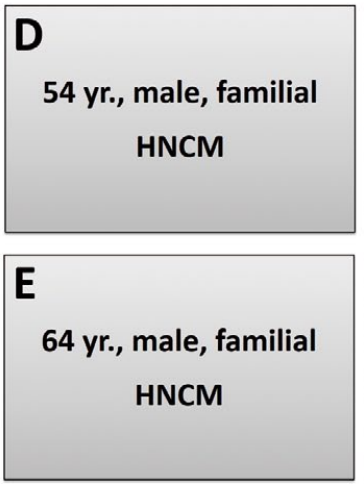
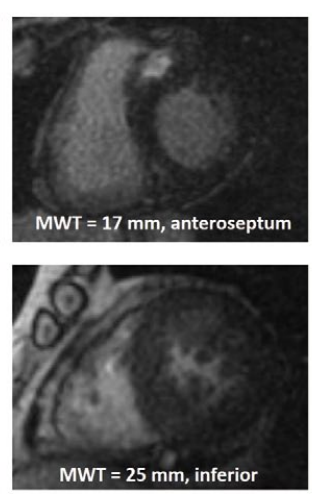

LGE - CMR
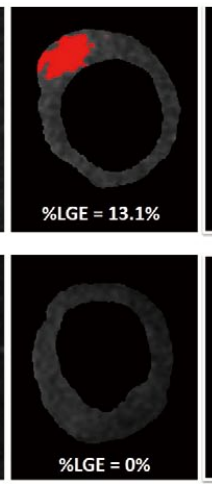

\section{Causative mutation}
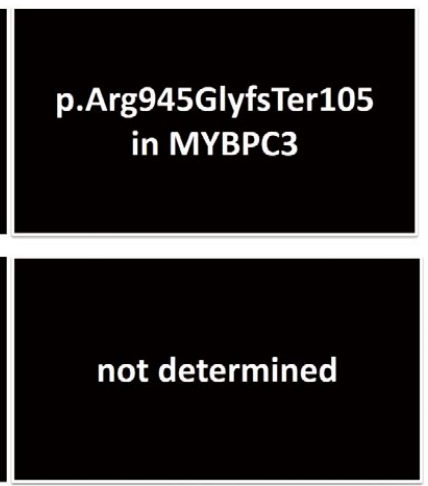

Figure 1. Evaluation of the extent of late gadolinium enhancement (LGE) in delayed gadolinium-enhanced cardiac magnetic resonance (CMR) and correlations between the extent of LGE and the mutation-positive or -negative status in representative HCM patients. (A) Area of LGE was measured in at least 4 short-axis slices. (B) Basal slice of CMR demonstrated LGE on anterioranteroseptal segments of the left ventricle. (C) Areas of LGE (red) at 6 SD above the normal myocardial signal were measured by ImageJ software and presented as the percentage of the LV area. (D) A 54-year-old male with HNCM, and a family history of sudden cardiac death, showed $13.1 \%$ LGE on CMR. Panel sequencing detected a large deletion in the MYBPC3 gene. (E) A 64-year-old male with HNCM showed neither LGE in his cardiac muscle nor any candidate variants. HNCM, hypertrophic non-obstructive cardiomyopathy.

cohort between 2008 and 2016 were included in the present study if they underwent CMR within 1 year of baseline echocardiography. Patients who exhibited a dilated phase at CMR evaluation were excluded. The diagnosis of HCM was based on the echocardiographic demonstration of LVH (maximal LV wall thickness $\geq 15 \mathrm{~mm}$ ) in the absence of other cardiac or systemic causes of LVH.5,10 The clinical assessment included medical history, detailed physical examination, blood tests, electrocardiography, echocardiography, and CMR.

\section{CMR}

CMR consisting of standard clinical scans was performed using 1.5-Tesla magnets. The LGE images were acquired $10 \mathrm{~min}$ after intravenous administration of $0.2 \mathrm{mmol} / \mathrm{kg}$ of gadolinium diethylenetriaminepentaacetic acid as previously described. ${ }^{11}$ Areas of LGE at 6 standard deviations (SD) above the normal myocardial signal were evaluated according to a method verified for detecting fibrosis. ${ }^{12,13}$ The LGE areas were measured by semiautomatic computer-assisted planimetry in each short-axis image using ImageJ by operators who were blind to genotype (Figure 1A-C). The $\%$ LGE was calculated by dividing the sum of the LGE areas by that of the total LV muscle areas to give the percentage. We defined LGE-positive as any level of \%LGE. In the absence of established methodology, an assessment of the variability between observations and observers was conducted to validate the accuracy of the obtained \%LGE value. The CMR sequences of all patients were analyzed by two trained analysts. The 1 st observer reviewed all the sequences after a 3-month interval to assess the intraobserver variability. The number of LGE segments was also evaluated using 17 myocardial segments. ${ }^{14}$

\section{Library Preparation and Targeted Sequencing}

DNA samples were isolated from peripheral white blood cells of each patient using a standard DNA extraction protocol. We designed an original gene panel that covered known HCM-related genes and genes possibly related with metabolic cascades (Table S1), and applied the panel to the first 15 patients. Multiplex polymerase chain reaction of the panel was performed using the Ion AmpliSeq Library Kit 2.0 (Thermo Fisher Scientific, Waltham, MA, USA). Sequencing was carried out on Ion PGM systems (Thermo Fisher Scientific). For the remaining 67 patients, we used a TruSight Cardio sequencing panel (Illumina, San Diego, CA, USA) following the manufacturer's instructions. This panel contains 174 genes that are related to cardiovascular disease, including known genes associated with familial HCM (Table S1). Variants, including single nucleotide polymorphisms, and short indels, were identified using the Genome Analysis Toolkit (GATK, Broad Institute, Boston, MA, USA) by calling raw variants.

\section{Bioinformatics Filtering Methods}

To identify causative variants among the HCM patients, we applied independent basic variant filtering processes that have commonly been reported in previous NGS studies. ${ }^{\mathbf{1 5}, 16}$ Variants were excluded if they did not meet the following criteria: (1) high quality based on the cutoff in 
depth of coverage, strand bias, and Genotype Quality score; (2) missense or protein-truncation (nonsense, essential splice-site, or frameshift) predicted by SnpEff; and (3) minor allele frequency $<0.01 \%$ referring to the Asian cohort in the 1000 Genome Project.

We defined a potentially causative mutation as pathogenic variants confirmed as follows: (1) literature review using various sources cited in the Human Mutation Database (HGMD) and ClinVar or (2) $\geq 1$ of the in silico prediction tools, including SIFT (scaled score $<0.05=$ deleterious), Polyphen 2 (scaled score $>20=$ probably damaging), and CADD (scaled C-score $>20=$ potentially pathogenic), which integrates diverse genome annotations and predicts the pathogenicity of non-synonymous variants in silico. ${ }^{17}$ The pathogenic mutations were confirmed using the Sanger method following a standard protocol (BigDye ${ }^{\circledR}$ Terminator v3.1 Cycle Sequencing Kit, Thermo Fisher Scientic) as previously described. ${ }^{\mathbf{1 8}}$

\section{Statistical Analysis}

All statistical analyses were conducted using SPSS Statistics (version 19, SPSS Inc., Chicago, IL, USA). Categorical variables are expressed as percentages. Continuous variables with a normal distribution are shown as the mean \pm SD. To assess the intra- and interobserver agreements, Lin's concordance correlation was used in accordance with a proposal that suggests that almost perfect agreement is indicated by $>0.99$, whereas poor agreement is indicated by $<0.9 .{ }^{19}$ Multiple logistic regression analysis was used to determine the independent predictors for mutation-positive HCM, based on Akaike's Information Criteria as modelselection criterion. Receiver-operating characteristic (ROC) analyses were used to estimate the discriminating ability for mutation-positive HCM for \%LGE and the Toronto genetic risk score, which consists of age, sex, hypertension, LV morphology, and the maximal wall thickness (MWT)/posterior wall thickness ratio. ${ }^{8}$ Sensitivity, specificity, positive predictive value (PPV), and negative predictive value (NPV) were defined as previously reported. ${ }^{20} \mathrm{~A}$ $\mathrm{P}$-value $<0.05$ was considered statistically significant.

\begin{tabular}{lc}
\hline \multicolumn{2}{|c|}{ Table 1. Clinical Characteristics, Electrocardiographic and } \\
\multicolumn{1}{|c}{ Echocardiographic Findings, and LGE on CMR } \\
Imaging of the 82 Study Patients With HCM
\end{tabular}

AF, atrial fibrillation; BNP, B-type natriuretic peptide; CMR, cardiac magnetic resonance; $\mathrm{HCM}$, hypertrophic cardiomyopathy; $\mathrm{HOCM}$, hypertrophic obstructive cardiomyopathy; LAD, left atrium diameter; LGE, late gadolinium enhancement; LVEF, left ventricular ejection fraction; LVMWT, left ventricular maximal wall thickness; NSVT, non-sustained ventricular tachycardia; SCD, sudden cardiac death; VF, ventricular fibrillation; VT, ventricular tachycardia.

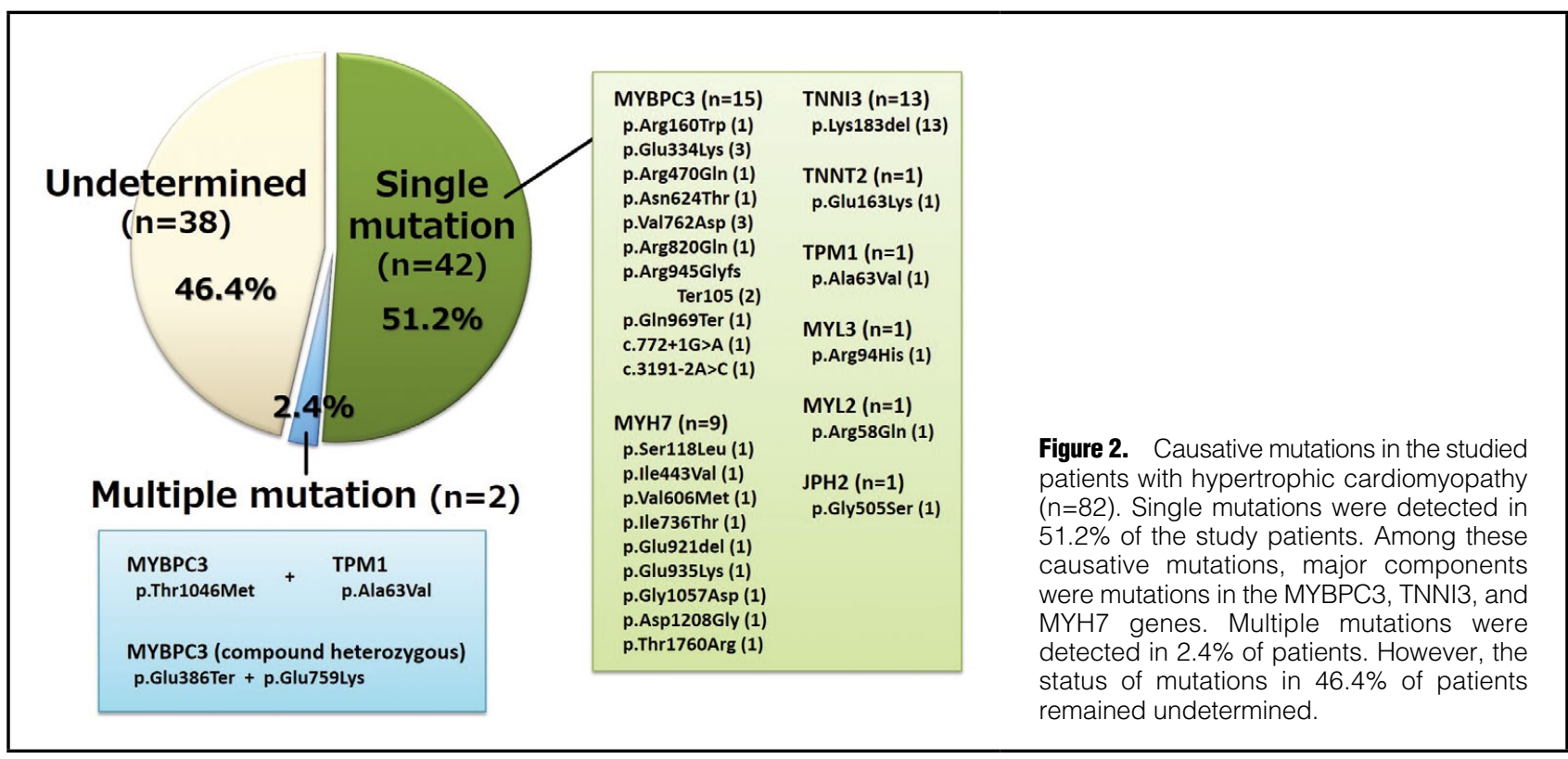


Table 2. Potentially Causative Mutations in the Study Patients With HCM Classified According to HGMD Registration and ClinVar Database

\begin{tabular}{|c|c|c|c|c|c|c|}
\hline Case no. & Gene & Chr. & Exon & $\begin{array}{l}\text { Position } \\
\text { (build 37) }\end{array}$ & $\begin{array}{c}\text { DNA } \\
\text { change }\end{array}$ & $\begin{array}{l}\text { Protein } \\
\text { change }\end{array}$ \\
\hline $\begin{array}{l}\text { HCM-001, 190, 208, 228, } \\
373,501,557,607,625 \text {, } \\
645,667,680,685\end{array}$ & TNNI3 & 19 & 7 & 55665397 & c.547_549delAAG & p.Lys183del \\
\hline HCM-018 & MYL3 & 3 & 3 & 46902192 & c. $281 \mathrm{G}>\mathrm{A}$ & p.Arg94His \\
\hline НCM-031 & MYBPC3 & 11 & 4 & 47371592 & c. $478 \mathrm{C}>\mathrm{T}$ & p.Arg160Trp \\
\hline HCM-038 & MYBPC3 & 11 & 18 & 47362715 & c. $1871 \mathrm{~A}>\mathrm{C}$ & p.Asn624Thr \\
\hline HCM-076 & TPM1 & 15 & 2 & 63336299 & c. $188 \mathrm{C}>\mathrm{T}$ & p.Ala63Val \\
\hline HCM-300, 539, 616 & MYBPC3 & 11 & 23 & 47360094 & c. $2285 \mathrm{~T}>\mathrm{A}$ & p.Val762Asp \\
\hline HCM-425, 567 & MYBPC3 & 11 & 26 & 47356663 & c.2833_2834delCG & p.Arg945GlyfsTer105 \\
\hline HCM-526 & МYBPC3 & 11 & 25 & 47359085 & c. $2459 \mathrm{G}>\mathrm{A}$ & p.Arg820GIn \\
\hline HCM-529 & MYH7 & 14 & 5 & 23901997 & c. $353 \mathrm{C}>\mathrm{T}$ & p.Ser118Leu \\
\hline HCM-534, 586, 617 & MYBPC3 & 11 & 12 & 47367848 & c. $1000 \mathrm{G}>\mathrm{A}$ & p.Glu334Lys \\
\hline HCM-546 & MYH7 & 14 & 36 & 23884594 & c. $5279 \mathrm{C}>\mathrm{G}$ & p.Thr1760Arg \\
\hline HCM-552 & MYH7 & 14 & 23 & 23893274 & c.2761_2763delGAG & p.Glu921del \\
\hline \multirow[t]{2}{*}{ HCM-565 } & MYBPC3 & 11 & 13 & 47365110 & c. $1156 \mathrm{G}>\mathrm{T}$ & p.Glu386Ter \\
\hline & MYBPC3 & 11 & 23 & 47360104 & c. $2275 \mathrm{G}>\mathrm{A}$ & p.Glu759Lys \\
\hline HCM-561 & JPH2 & 20 & 4 & 42744802 & c. $1513 G>A$ & p.Gly505Ser \\
\hline HCM-580 & MYBPC3 & 11 & - & 47369974 & c. $772+1 \mathrm{G}>\mathrm{A}$ & - \\
\hline HCM-588 & MYH7 & 14 & 27 & 23889157 & c. $3623 A>G$ & p.Asp1208Gly \\
\hline HCM-591 & MYH7 & 14 & 25 & 23891464 & c. $3170 \mathrm{G}>\mathrm{A}$ & p.Gly1057Asp \\
\hline HCM-592 & TNNT2 & 1 & 12 & 201332507 & c. $517 \mathrm{G}>\mathrm{A}$ & p.Glu163Lys \\
\hline HCM-601 & MYH7 & 14 & 16 & 23896866 & c. $1816 \mathrm{G}>\mathrm{A}$ & p.Val606Met \\
\hline HCM-602 & MYL2 & 12 & 3 & 111352091 & c. $173 \mathrm{G}>\mathrm{A}$ & p.Arg58Gln \\
\hline \multirow[t]{2}{*}{ HCM-610 } & MYBPC3 & 11 & 29 & 47355161 & c. $3137 \mathrm{C}>\mathrm{T}$ & p.Thr1046Met \\
\hline & TPM1 & 15 & 2 & 63336299 & c. $188 \mathrm{C}>\mathrm{T}$ & p.Ala63Val \\
\hline HCM-611 & MYH7 & 14 & 14 & 23898244 & c. $1327 A>G$ & p.lle443Val \\
\hline HCM-623 & MYH7 & 14 & 20 & 23894983 & c. $2207 \mathrm{~T}>\mathrm{C}$ & p.Ile736Thr \\
\hline HCM-650 & MYBPC3 & 11 & - & 47354886 & c. $3191-2 A>C$ & - \\
\hline HCM-677 & MYH7 & 14 & 23 & 23893235 & c. $2803 \mathrm{G}>\mathrm{A}$ & p.Glu935Lys \\
\hline HCM-681 & MYBPC3 & 11 & 27 & 47356593 & c. $2905 \mathrm{C}>\mathrm{T}$ & p.GIn969Ter \\
\hline HCM-690 & MYBPC3 & 11 & 14 & 47364429 & c. $1409 \mathrm{G}>\mathrm{A}$ & p.Arg470GIn \\
\hline
\end{tabular}

SIFT scores (ranging from 0 to 1 ) were calculated by SIFT version 5.2.2; a SIFT score $<0.05$ considered as deleterious. PolyPhen-2 scores (ranging from 0 to 1) were calculated by PolyPhen-2 version 2.2.2; a PolyPhen-2 score $>0.85$ considered as probably damaging. The cutoff of CADD score on deleteriousness to identify potentially pathogenic variants was 20. CADD, Combined Annotation Dependent Depletion; Chr, chromosome; DM, damaging mutation; HCM, hypertrophic cardiomyopathy; Het, heterozygous; HGMD, Human Gene Mutation Database; PolyPhen-2, Polymorphism Phenotyping v2 Score; Position, nucleotide position; SIFT, Sorting Intolerant from Tolerant.

(Table 2 continued the next page.) 


\begin{tabular}{|c|c|c|c|c|c|}
\hline Genotype & $\begin{array}{l}\text { MAF } \\
(\%)\end{array}$ & SIFT & PolyPhen-2 & $\begin{array}{l}\text { CADD } \\
\text { score }\end{array}$ & $\begin{array}{c}\text { Variant } \\
\text { category }\end{array}$ \\
\hline Het & 0.00 & - & - & $\begin{array}{c}\text { Potentially } \\
\text { pathogenic (22.4) }\end{array}$ & $\mathrm{DM}^{21}$ \\
\hline Het & 0.00 & Deleterious (0.02) & $\begin{array}{l}\text { Benign } \\
(0.009)\end{array}$ & $\begin{array}{c}\text { Potentially } \\
\text { pathogenic }(25.5)\end{array}$ & $\mathrm{DM}^{15}$ \\
\hline Het & 0.00 & Deleterious (0) & $\begin{array}{c}\text { Probably } \\
\text { damaging }(0.993)\end{array}$ & $\begin{array}{c}\text { Potentially } \\
\text { pathogenic (28.8) }\end{array}$ & $\mathrm{DM}^{36}$ \\
\hline Het & 0.00 & Tolerated $(0.27)$ & $\begin{array}{l}\text { Benign } \\
(0.259)\end{array}$ & $\begin{array}{c}\text { Potentially } \\
\text { pathogenic (23.4) }\end{array}$ & Not listed \\
\hline Het & 0.00 & Tolerated $(0.11)$ & $\begin{array}{l}\text { Benign } \\
(0.034)\end{array}$ & $\begin{array}{c}\text { Potentially } \\
\text { pathogenic (22.9) }\end{array}$ & $\mathrm{DM}^{37}$ \\
\hline Het & 0.00 & Deleterious (0) & $\begin{array}{c}\text { Possibly } \\
\text { damaging }(0.893)\end{array}$ & $\begin{array}{c}\text { Potentially } \\
\text { pathogenic (29.0) }\end{array}$ & $\mathrm{DM}^{18}$ \\
\hline Het & 0.00 & - & - & $\begin{array}{l}\text { Not indicated } \\
(16.9)\end{array}$ & $\mathrm{DM}^{36}$ \\
\hline Het & 0.00 & Deleterious (0.01) & $\begin{array}{c}\text { Probably } \\
\text { damaging }(0.954)\end{array}$ & $\begin{array}{c}\text { Potentially } \\
\text { pathogenic }(35.0)\end{array}$ & $\mathrm{DM}^{36}$ \\
\hline Het & 0.00 & Deleterious (0) & $\begin{array}{l}\text { Benign } \\
(0.37)\end{array}$ & $\begin{array}{c}\text { Potentially } \\
\text { pathogenic (28.1) }\end{array}$ & Not listed \\
\hline Het & 0.00 & Tolerated $(0.05)$ & $\begin{array}{l}\text { Benign } \\
(0.344)\end{array}$ & $\begin{array}{c}\text { Potentially } \\
\text { pathogenic (24.9) }\end{array}$ & $\mathrm{DM}^{36}$ \\
\hline Het & 0.00 & Deleterious (0.01) & $\begin{array}{c}\text { Probably } \\
\text { damaging (1) }\end{array}$ & $\begin{array}{c}\text { Potentially } \\
\text { pathogenic (29.7) }\end{array}$ & Not listed \\
\hline Het & 0.00 & - & - & $\begin{array}{c}\text { Potentially } \\
\text { pathogenic (22.1) }\end{array}$ & Not listed \\
\hline Het & 0.00 & - & - & $\begin{array}{c}\text { Potentially } \\
\text { pathogenic (38.0) }\end{array}$ & Not listed \\
\hline Het & 0.00 & Deleterious (0.03) & $\begin{array}{c}\text { Probably } \\
\text { damaging }(0.956)\end{array}$ & $\begin{array}{c}\text { Potentially } \\
\text { pathogenic }(35.0)\end{array}$ & Not listed \\
\hline Het & 0.00 & Tolerated $(0.71)$ & $\begin{array}{l}\text { Benign } \\
(0.003)\end{array}$ & $\begin{array}{l}\text { Not indicated } \\
(5.0)\end{array}$ & $\mathrm{DM}^{38}$ \\
\hline Het & 0.00 & - & - & $\begin{array}{c}\text { Potentially } \\
\text { pathogenic (26.4) }\end{array}$ & Not listed \\
\hline Het & 0.00 & Deleterious (0) & $\begin{array}{c}\text { Probably } \\
\text { damaging (1) }\end{array}$ & $\begin{array}{c}\text { Potentially } \\
\text { pathogenic (27.3) }\end{array}$ & Not listed \\
\hline Het & 0.00 & Deleterious (0.03) & $\begin{array}{c}\text { Probably } \\
\text { damaging (0.999) }\end{array}$ & $\begin{array}{c}\text { Potentially } \\
\text { pathogenic (22.4) }\end{array}$ & $\mathrm{DM}^{39}$ \\
\hline Het & 0.00 & - & - & $\begin{array}{c}\text { Potentially } \\
\text { pathogenic (34.0) }\end{array}$ & $\mathrm{DM}^{40}$ \\
\hline Het & 0.00 & Deleterious (0) & $\begin{array}{c}\text { Probably } \\
\text { damaging }(0.907)\end{array}$ & $\begin{array}{c}\text { Potentially } \\
\text { pathogenic (26.8) }\end{array}$ & $\mathrm{DM}^{41}$ \\
\hline Het & 0.00 & Tolerated $(0.16)$ & $\begin{array}{c}\text { Probably } \\
\text { damaging (0.995) }\end{array}$ & $\begin{array}{c}\text { Potentially } \\
\text { pathogenic (27.7) }\end{array}$ & $\mathrm{DM}^{42}$ \\
\hline Het & 0.00 & Tolerated $(0.06)$ & $\begin{array}{l}\text { Benign } \\
(0.044)\end{array}$ & $\begin{array}{c}\text { Potentially } \\
\text { pathogenic (18.6) }\end{array}$ & $\mathrm{DM}^{36}$ \\
\hline Het & 0.00 & Tolerated $(0.11)$ & $\begin{array}{l}\text { Benign } \\
(0.034)\end{array}$ & $\begin{array}{c}\text { Potentially } \\
\text { pathogenic (22.9) }\end{array}$ & $\mathrm{DM}^{37}$ \\
\hline Het & 0.00 & Tolerated $(0.25)$ & $\begin{array}{c}\text { Probably } \\
\text { damaging (0.99) }\end{array}$ & $\begin{array}{c}\text { Potentially } \\
\text { pathogenic (22.2) }\end{array}$ & Not listed \\
\hline Het & 0.00 & Tolerated $(0.1)$ & $\begin{array}{c}\text { Probably } \\
\text { damaging }(0.999)\end{array}$ & $\begin{array}{c}\text { Potentially } \\
\text { pathogenic (24.7) }\end{array}$ & $\mathrm{DM}^{43}$ \\
\hline Het & 0.00 & - & - & $\begin{array}{c}\text { Potentially } \\
\text { pathogenic (24.0) }\end{array}$ & Not listed \\
\hline Het & 0.00 & Deleterious (0.04) & $\begin{array}{c}\text { Probably } \\
\text { damaging }(0.948)\end{array}$ & $\begin{array}{c}\text { Potentially } \\
\text { pathogenic (33.0) }\end{array}$ & $\mathrm{DM}^{44}$ \\
\hline Het & 0.00 & - & - & $\begin{array}{c}\text { Potentially } \\
\text { pathogenic (38.0) }\end{array}$ & $\mathrm{DM}^{45}$ \\
\hline Het & 0.00 & - & - & $\begin{array}{c}\text { Potentially } \\
\text { pathogenic (34.0) }\end{array}$ & $\mathrm{DM}^{46}$ \\
\hline
\end{tabular}


Table 3. Logistic Regression Analysis of Clinical Findings in Predicting the Mutation-Positive Status of Patients With HCM ( $\mathrm{n}=82$ )

\begin{tabular}{|c|c|c|c|c|c|c|c|c|c|}
\hline \multirow{3}{*}{ Variable } & \multirow{2}{*}{\multicolumn{3}{|c|}{ Univariate }} & \multicolumn{6}{|c|}{ Multivariate } \\
\hline & & & & \multicolumn{3}{|c|}{ Model 1} & \multicolumn{3}{|c|}{ Model 2} \\
\hline & OR & $95 \% \mathrm{Cl}$ & $P$ value & OR & $95 \% \mathrm{Cl}$ & $P$ value & OR & $95 \% \mathrm{Cl}$ & $P$ value \\
\hline Age & 0.97 & $0.94-0.99$ & $0.02^{*}$ & & & & & & \\
\hline Male & 0.42 & $0.17-1.03$ & 0.06 & 0.03 & $0.0006-0.41$ & $0.028^{*}$ & & & \\
\hline Familial & 16.7 & $5.08-77.6$ & $0.00003^{*}$ & 7.32 & $0.91-100.5$ & 0.082 & 8.01 & $0.99-112.2$ & 0.072 \\
\hline $\mathrm{AF}$ & 0.85 & $0.19-3.84$ & 0.83 & & & & & & \\
\hline BNP & 1.0 & $0.99-1.0$ & 0.591 & & & & & & \\
\hline Fragmented QRS & 2.53 & $1.05-6.34$ & $0.042^{*}$ & & & & & & \\
\hline HOCM & 1.57 & $0.52-5.07$ & 0.431 & & & & & & \\
\hline LAD & 0.97 & $0.9-1.03$ & 0.319 & & & & & & \\
\hline LVMWT & 1.06 & $0.98-1.17$ & 0.172 & & & & & & \\
\hline LVEF & 0.99 & $0.95-1.03$ & 0.618 & & & & & & \\
\hline Family history of SCD & 6.0 & $1.47-40.7$ & $0.026^{\star}$ & & & & & & \\
\hline VF/VT & 8.22 & $1.41-156.5$ & 0.052 & & & & & & \\
\hline NSVT & 2.21 & $0.56-10.9$ & 0.278 & & & & & & \\
\hline Toronto score & 1.17 & $1.07-1.31$ & $0.0024^{*}$ & & & & 1.11 & $0.96-1.54$ & 0.166 \\
\hline \%LGE on CMR & 1.77 & $1.42-2.46$ & $0.00002^{*}$ & 2.12 & $1.51-3.83$ & $0.0009^{*}$ & 1.75 & $1.38-1.54$ & $0.0002^{*}$ \\
\hline
\end{tabular}

${ }^{*} \mathrm{P}<0.05$. OR, odds ratio. Other abbreviations as in Table 1.

Differences between mutation-positive patients within each $\%$ LGE category were analyzed using the Cochrane-Armitage test to assess the trend of proportions.

\section{Ethical Considerations}

The Ethics Committee of Kanazawa University approved this study. All procedures followed were in accordance with the ethical standards of the responsible committee on human experimentation (institutional and national) and with the Helsinki Declaration of 1975, as revised in 2008. Written informed consent was given by all participants or their guardians.

\section{Results}

\section{Characteristics of the Study Patients}

The clinical characteristics of the study patients are listed in Table 1: 82 unrelated patients ( 47 men, mean age $=55.4$ years, familial cases $=29$ ) with clinically affected HCM were evaluated. The mean LVMWT was $19.2 \mathrm{~mm}$. CMR analysis showed that 60 patients had LGE in a total of 205 segments $(2.5 \pm 2.8$ segments/patient) and the average $\%$ LGE was $9.91 \%$. The measurement protocol of \%LGE reached a sufficiently high intra- and interobserver reproducibility (Lin's concordance correlation coefficient $=0.95$ and 0.91 , respectively).

\section{Panel-Wide Sequencing}

Targeted sequencing was performed in $82 \mathrm{HCM}$ patients. In the 15 patients using our original 21-gene panel, the mean read length was 149.2 base pairs, the mean sequencing coverage depth was $379.4 \times$ per base across the target genes, and the coverage rate for the target coding lesions $(20 \times)$ was $97.6 \%$. In the 67 patients using the TruSight Cardio panel, the mean read length was 278.4 base pairs, the mean sequencing coverage depth was $456.2 \times$, and the coverage rate for the target coding lesions $(20 \times)$ was $99.8 \%$. A single mutation was detected in $51.2 \%$ of the studied patients with HCM (Figure 2). Among these causative mutations, major components were mutations in the MYBPC3 gene $(n=15)$, the TNNI3 gene $(n=13)$, and the MYH7 gene $(n=9)$. Multiple mutations were detected in $2.4 \%$ of all patients. However, the status of mutations in $46.4 \%$ of the patients remained undetermined.

Detailed information about potentially causative mutations is listed in Table 2 according to evidence-based assessment or in silico prediction. Each mutation was confirmed by Sanger sequencing. A representative case is shown in Figure S1. The proband, a 49-year-old man with clinically affected HCM, showed LGE confined to the basal anteroseptal wall on CMR in a pattern typical for HCM, but LVH was not as prominent (LVMWT=15.1 mm). Panel-wide sequencing revealed a pathogenic heterozygous p.Lys183del mutation in the TNNI3 exon $7,{ }^{21}$ which was confirmed by Sanger sequencing.

\section{Correlations Between Presence of Mutations and Clinical Parameters in HCM}

We first assessed whether LGE on CMR is an independent factor causing an increase in the pre-genetic test probability of mutation-positive HCM. Multivariate logistic regression analyses revealed that the \%LGE on CMR was independently associated with the presence of mutations in patients with clinically affected HCM after adjustments for sex and familial situation (odds ratio [OR], 2.12; 95\% confidence interval [CI], 1.51-3.83; $\mathrm{P}=0.0009$; model 1 in Table 3) as the most parsimonious model based on Akaike's Information Criterion. As a result of model 2, which added a Toronto score integrating conventional risk factors such as younger age, female sex, and LV morphology for mutation-positive HCM into model 1, the \%LGE still remained an independent predictor for the presence of sarcomere mutations $(\mathrm{OR}, 1.8 ; 95 \% \mathrm{CI}, 1.4-1.5 ; \mathrm{P}=0.0002$; model 2 in Table 3).

ROC plots of \%LGE demonstrated an extremely high AUC for mutation-positive HCM (AUC=0.96) (Figure 3). When the cutoff value was set at $8.1 \%$, the sensitivity, specificity, PPV, and NPV of \%LGE were $93.2 \%, 89.5 \%$, $91.1 \%$, and $91.9 \%$, respectively. The AUC of $\%$ LGE was greater than that of the Toronto genetic risk score 
(AUC $=0.69, \mathrm{P}=0.00002$ ), which is reported as an accurate predictive tool for mutation-positive HCM. ${ }^{8}$ The AUC of the \%LGE was greater than that of LGE-positive status (AUC=0.79, $\mathrm{P}=0.000008$ ).

Correlations between the extent of LGE and mutationpositive or -negative status are shown in representative HCM patients (Figure 1). A 54-year-old male with HCM, who had a family history of sudden cardiac death, showed asymmetric septal hypertrophy $(17 \mathrm{~mm})$ and $13.1 \%$ LGE in the anteroseptal wall on CMR. Panel sequencing detected a relatively large deletion in exon 26 of MYBPC 3 (Figure 1D). This variant is reported as a causative mutation for HCM (Table 2). On the other hand, a 64-year-old male with moderate LVH predominantly in the inferior wall (LVMWT $=25 \mathrm{~mm}$ ) did not show LGE on CMR. Panel sequencing did not detect any pathogenic mutations (Figure 1E).

We then investigated whether the rate of detection of mutation-positive HCM using genetic testing could be improved according to increased extent of LGE. The proportion of mutation carriers significantly increased with increasing \%LGE $(\mathrm{P}<0.01$ for trends, Figure 4$)$; $91 \%$ of patients with LGE $\geq 8.1 \%$ had disease-causing mutations. Conversely, among 37 patients with LGE $<8.1 \%$, only 3 were carriers of a pathogenic mutation $(8.1 \%)$. Together, these findings suggested that the extent of LGE in clinically affected HCM patients strongly increases the pre-test probability of patients having a disease-causing mutation.

\section{Discussion}

The present study, which focused on the genetic basis of myocardial scarring in HCM, made 3 major findings: (1) the extent of a myocardial scar determined by LGE on CMR was an independent factor for predicting mutationpositive HCM (OR 2.12 [95\% CI 1.51-3.83], P<0.01); (2) the proportion of mutation-positive $\mathrm{HCM}$ increased linearly relative to \%LGE ( $\mathrm{P}<0.01$ for trends); and (3) LGE (cutoff $>8.1 \%$ ) strongly discriminated mutation-positive

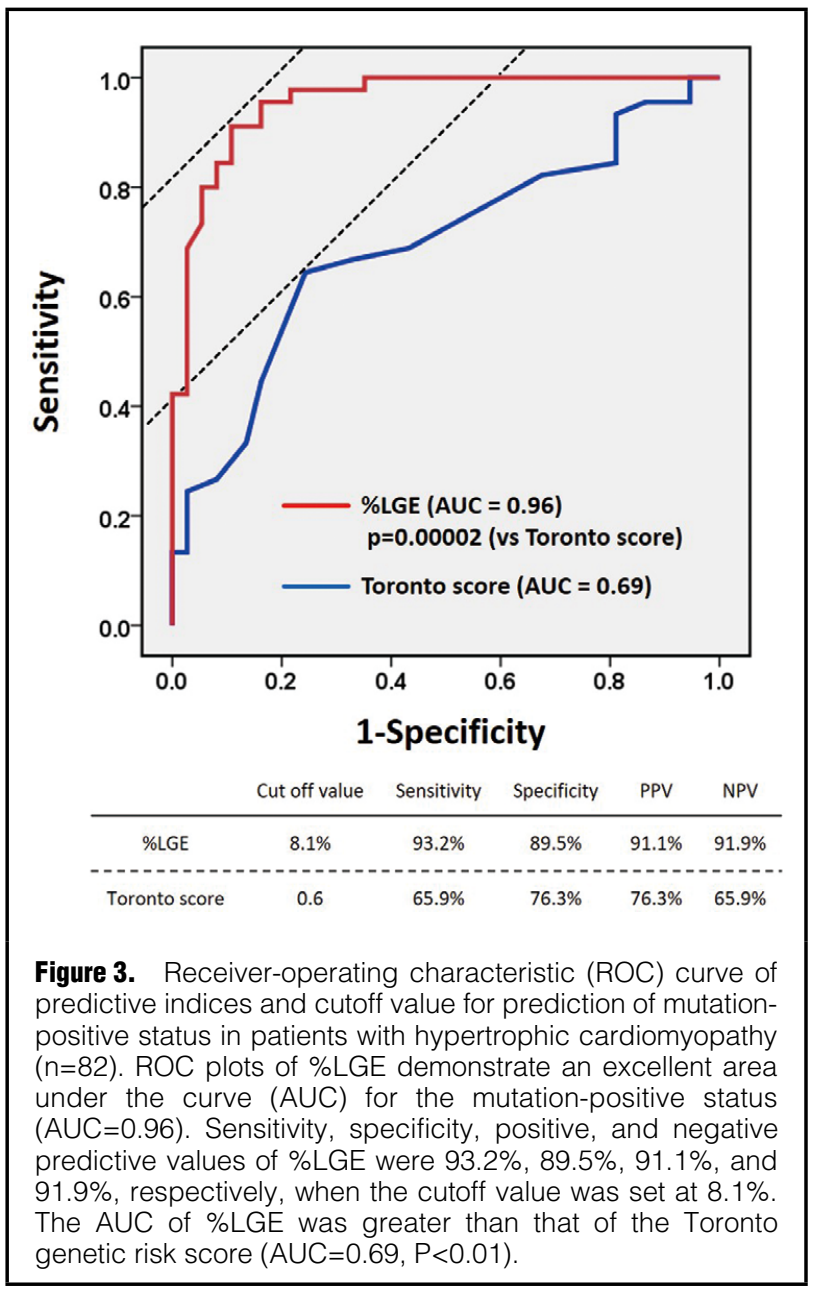

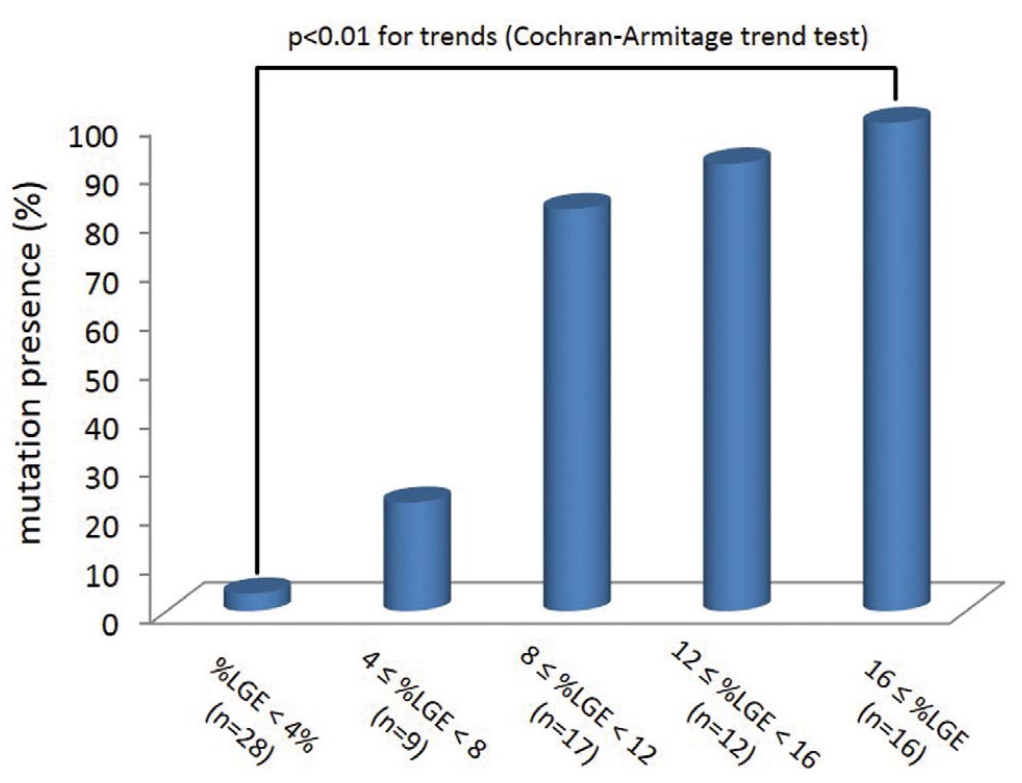

Figure 4. Frequency of mutation-positive hypertrophic cardiomyopathy $(\mathrm{HCM})$ at different extents of late gadolinium enhancement (LGE). Bar graph shows the presence of mutations according to the extent of LGE. Causative mutation for $\mathrm{HCM}$ was present predominantly in the group with a high $\%$ LGE. $P<0.001$ for trends was obtained for all comparisons across \%LGE categories. 
from mutation-negative HCM in a clinically affected HCM population. These results demonstrated the close relationship between the presence of sarcomere gene mutations and the extent of LGE.

\section{Myocardial Scarring as a Primary Expression of HCM}

Myocardial scarring, often referred to as replacement fibrosis, is assumed to occur subsequent to cardiac muscle cell disorganization, even in the absence of epicardial coronary artery disease. ${ }^{6,22}$ Recent data indicated that interstitial fibrosis may represent a primary phenotypic expression of HCM and is not necessarily a time-related feature. ${ }^{23,24}$ Several studies have shown early activation of profibrotic genetic pathways in mice models with sarcomere gene mutations. ${ }^{25,26}$ Thus, it is considered that myocardial scars occur as a result of focal myocardial damage in the hypertrophied myocardium whereas interstitial fibrosis is primarily induced by sarcomere gene mutations in HCM.

Intriguingly, in this study, NGS enabled us to reveal direct associations between myocardial scars and sarcomere gene mutations in HCM; LGE was the only independent factor that could predict the identification of sarcomere gene mutations, even after adjusting for age, sex, familial situation, and the extent of LVMWT (multivariate regression model 2 in Table 3). These findings suggested that myocardial scars, when determined by LGE, might be directly induced by a sarcomere gene mutation, irrespective of the extent of LVMWT. This hypothesis may be supported by previous clinical and experimental studies. HCM patients show a greater extent of myocardial scarring than patients with LVH caused by pressure overload such as hypertension or aortic stenosis. ${ }^{27}$ The physiological basis of LGE is mainly based on prolonged washout of the contrast agent, which is related to decreased capillary density within the fibrotic myocardial tissue. Moreover, myocytes with sarcomere gene mutations leads to expansion of the interstitial matrix, which may in turn lead to increased contrast agent retained within fibrotic tissue because of the decreased capillary density in the activation cascade of myocyte enhancer factor- $2 .{ }^{28} \mathrm{An}$ in vivo animal study demonstrated that myosin regulatory light chain transgenic HCM mice exhibited myocardial scarring even before the development of LVH.7 Although the mechanism by which sarcomere gene mutations lead to myocardial scarring remains unclear, severely narrowed small coronary arteries, a characteristic feature of HCM, also may be directly caused by the sarcomere gene mutations, partly explaining this association. ${ }^{12,29}$ Further studies are needed to determine the pathogenesis of small coronary artery disease in HCM.

\section{Novel Interpretation of the Extent of LGE Based on Molecular Diagnosis of HCM}

Although LGE has been studied as a tissue characterization technique in $\mathrm{HCM}, \mathbf{4 0}$ it is often challenging to obtain quantitative quality LGE imaging in HCM patients, because of the lack of a universally accepted protocol for acquisition and evaluation, difficulty in defining the reference area, pathophysiological diversity of the disease, and mechanical and human conditions at the time of image acquisition. When we analyzed delayed-enhancement images at $6 \mathrm{SD}$ as previously reported, ${ }^{12,31}$ there were strong linear correlations between observations and observers in the measurement of \%LGE ( $r \geq 0.9$ for 2 comparisons in Figure S2). Reproducibility was supported by good intra- and interobserver correlations between \%LGE (Lin's concordance correlation coefficient $=0.95$ and 0.91 , respectively).

In previous CMR studies, variation in the extent of LGE was considered to reflect heterogeneity of HCM phenotypes. ${ }^{12}$ However, our data suggested that HCM with an increased extent of LGE may be genetically different from HCM with absence or a low extent of LGE, even though these two groups are indistinguishable based on LV morphology. A recent retrospective cohort study revealed that a subgroup without a family history or sarcomere gene mutations should be classified as a previously unrecognized subgroup known as "nonfamilial HCM" because of its prognostic features with later onset and less risk of major cardiac events. ${ }^{8}$ Thus, clinically affected HCM patients exhibiting either none or only a small extent of LGE could be classified into the subgroup with different underlying pathogenesis.

These observations may also have an effect on strategies of risk stratification of HCM. Previous data showed that HCM with none or a small extent of LGE is associated with favorable clinical outcomes. ${ }^{32}$ At the same time, HCM patients who do not have a sarcomere gene mutation may show better prognosis than those harboring such mutations. ${ }^{\mathbf{8} 33,34}$ Because our study revealed direct associations between the extent of LGE and a sarcomere gene mutation, advanced expertise from the ongoing HCMR study (NCT 01915615$)^{35}$ is anticipated to clarify the long-term clinical course in HCM, specifically in the previously unrecognized subgroup of mutation-negative HCM without significant LGE.

\section{Study Limitations}

Several limitations remain in this study. First, pathogenic mutations within those genes not included in the panels may have been missed. However, our gene panel covered sarcomere genes and metabolic cascade-related genes, indicating that known HCM-causing genes might not be associated with cases of LVH in which disease-causing mutations were not identified in this study. Second, large deletions might not be detected by NGS. However, this possibility is quite low because we carefully checked the average read length and coverage depth in each sample. Additional whole-exome sequencing or whole-genome sequencing is warranted to investigate the nature of $\mathrm{LVH}$ related to unknown genes in HCM patients without sarcomere mutations. Third, our data did not include evaluation of T1 mapping, which is sensitive to detecting fibrotic areas, because of technical limitations in the initial cases.

\section{Conclusions}

LGE on CMR was independently associated with the presence of mutations in clinically affected HCM patients. HCM with increased myocardial scarring may be genetically different from HCM with little or no extent of myocardial scarring.

\section{Acknowledgments}

We express special thanks to Professor Atsushi Tajima (for the use of NGS facilities), Kazuyoshi Hosomichi, PhD (for valuable discussion and comments), and Ms. Yoko Iwauchi (for technical assistance) in the Department of Bioinformatics and Genomics, Kanazawa University. The authors also thank Takako Obayashi for technical assistance with the laboratory experiments. 


\section{Conflict of Interest / Sources of Funding}

None.

\section{References}

1. Seidman JG, Seidman C. The genetic basis for cardiomyopathy: From mutation identification to mechanistic paradigms. Cell 2001; 23: 557-567.

2. Maron BJ, Ommen SR, Semsarian C, Spirito P, Olivotto I, Maron MS. Hypertrophic cardiomyopathy: Present and future, with translation into contemporary cardiovascular medicine. $J$ Am Coll Cardiol 2014; 64: 83-99.

3. Konno T, Chang S, Seidman JG, Seidman CE. Genetics of hypertrophic cardiomyopathy. Curr Opin Cardiol 2010; 25: 205 209

4. Rubinshtein R, Glockner JF, Ommen SR, Araoz PA, Ackerman $\mathrm{MJ}$, Sorajja $\mathrm{P}$, et al. Characteristics and clinical significance of late gadolinium enhancement by contrast-enhanced magnetic resonance imaging in patients with hypertrophic cardiomyopathy. Circ Heart Fail 2010; 3: 51-58.

5. Gersh BJ, Maron BJ, Bonow RO, Dearani JA, Fifer MA, Link MS, et al. 2011 ACCF/AHA Guideline for the Diagnosis and Treatment of Hypertrophic Cardiomyopathy: A report of the American College of Cardiology Foundation/American Heart Association Task Force on Practice Guidelines. Developed in collaboration with the American Association for Thoracic Surgery, American Society of Echocardiography, American Society of Nuclear Cardiology, Heart Failure Society of America, Heart Rhythm Society, Society for Cardiovascular Angiography and Interventions, and Society of Thoracic Surgeons. J Am Coll Cardiol 2011; 58: $2212-\mathrm{e} 260$.

6. Shirani J, Pick R, Roberts WC, Maron BJ. Morphology and significance of the left ventricular collagen network in young patients with hypertrophic cardiomyopathy and sudden cardiac death. J Am Coll Cardiol 2000; 35: 36-44.

7. Huang W, Liang J, Kazmierczak K, Muthu P, Duggal D, Farman GP, et al. Hypertrophic cardiomyopathy associated Lys104Glu mutation in the myosin regulatory light chain causes diastolic disturbance in mice. J Mol Cell Cardiol 2014; 74: 318 329.

8. Ingles J, Burns C, Bagnall RD, Lam L, Yeates L, Sarina T, et al. Nonfamilial hypertrophic cardiomyopathy: Prevalence, natural history, and clinical implications. Circ Cardiovasc Genet 2017; 10: $\mathrm{e} 001620$.

9. Ellims AH, Iles LM, Ling LH, Chong B, Macciocca I, Slavin GS et al. A comprehensive evaluation of myocardial fibrosis in hypertrophic cardiomyopathy with cardiac magnetic resonance imaging: Linking genotype with fibrotic phenotype. Eur Heart $J$ Cardiovasc Imaging 2014; 15: $1108-1116$.

10. Authors/Task Force members, Elliott PM, Anastasakis A, Borger MA, Borggrefe M, Cecchi F, et al. 2014 ESC Guidelines on diagnosis and management of hypertrophic cardiomyopathy: The Task Force for the Diagnosis and Management of Hypertrophic Cardiomyopathy of the European Society of Cardiology (ESC). Eur Heart J 2014; 35: 2733-2779.

11. Nagata Y, Konno T, Fujino N, Hodatsu A, Nomura A, Hayashi $\mathrm{K}$, et al. Right ventricular hypertrophy is associated with cardiovascular events in hypertrophic cardiomyopathy: Evidence from study with magnetic resonance imaging. Can J Cardiol 2015; 31: $702-708$.

12. Moravsky G, Ofek E, Rakowski H, Butany J, Williams L, Ralph-Edwards A, et al. Myocardial fibrosis in hypertrophic cardiomyopathy: Accurate reflection of histopathological findings by CMR. J Am Coll Cardiol Img 2013; 6: 587-596.

13. Konno T, Nagata Y, Teramoto R, Fujino N, Nomura A, Tada $\mathrm{H}$, et al. Usefulness of electrocardiographic voltage to determine myocardial fibrosis in hypertrophic cardiomyopathy. Am J Cardiol 2016; 117: 443-449.

14. Cerqueira MD, Weissman NJ, Dilsizian V, Jacobs AK, Kaul S, Laskey WK, et al. Standardized myocardial segmentation and nomenclature for tomographic imaging of the heart: A statement for healthcare professionals from the Cardiac Imaging Committee of the Council on Clinical Cardiology of the American Heart Association. Circulation 2002; 105: 539-542.

15. Nomura A, Tada H, Teramoto R, Konno T, Hodatsu A, Won $\mathrm{HH}$, et al. Whole exome sequencing combined with integrated variant annotation prediction identifies a causative myosin essential light chain variant in hypertrophic cardiomyopathy. $J$ Cardiol 2016; 67: 133-139.
16. Hayashi K, Konno T, Tada H, Tani S, Liu L, Fujino N, et al. Functional characterization of rare variants implicated in susceptibility to lone atrial fibrillation. Circ Arrhythm Electrophysiol 2015; 8: 1095-1104.

17. Tada H, Kawashiri MA, Nohara A, Saito R, Tanaka Y, Nomura $\mathrm{A}$, et al. Whole exome sequencing combined with integrated variant annotation prediction identifies asymptomatic Tangier disease with compound heterozygous mutations in ABCA1 gene. Atherosclerosis 2015; 240: 324-329.

18. Hodatsu A, Konno T, Hayashi K, Funada A, Fujita T, Nagata $\mathrm{Y}$, et al. Compound heterozygosity deteriorates phenotypes of hypertrophic cardiomyopathy with founder MYBPC3 mutation: Evidence from patients and zebrafish models. Am J Physiol Heart Circ Physiol 2014; 307: H1594-H1604.

19. McBride GB. A proposal for strength-of-agreement criteria for Lin's concordance correlation coefficient. Prepared for Ministry of Health. NIWA client report: HAM 2005-2062. Hamiliton, NZ: National Institute of Water \& Atmospheric Research, May 2005.

20. Konno T, Shimizu M, Ino H, Yamaguchi M, Terai H, Uchiyama $\mathrm{K}$, et al. Diagnostic value of abnormal Q waves for identification of preclinical carriers of hypertrophic cardiomyopathy based on a molecular genetic diagnosis. Eur Heart J 2004; 25: 246-251.

21. Kokado H, Shimizu M, Yoshio H, Ino H, Okeie K, Emoto Y, et al. Clinical features of hypertrophic cardiomyopathy caused by a Lys183 deletion mutation in the cardiac troponin I gene. Circulation 2000; 102: 663-669.

22. Maron BJ, Anan TJ, Roberts WC. Quantitative analysis of the distribution of cardiac muscle cell disorganization in the left ventricular wall of patients with hypertrophic cardiomyopathy. Circulation 1981; 63: 882-894.

23. Ho CY, Lopez B, Coelho-Filho OR, Lakdawala NK, Cirino AL, Jarolim P, et al. Myocardial fibrosis as an early manifestation of hypertrophic cardiomyopathy. N Engl J Med 2010; 363: $552-$ 563.

24. Crilley JG, Boehm EA, Blair E, Rajagopalan B, Blamire AM, Styles P, et al. Hypertrophic cardiomyopathy due to sarcomeric gene mutations is characterized by impaired energy metabolism irrespective of the degree of hypertrophy. J Am Coll Cardiol 2003; 41: 1776-1782.

25. Konno T, Chen D, Wang L, Wakimoto H, Teekakirikul $\mathrm{P}$, Nayor M, et al. Heterogeneous myocyte enhancer factor-2 (Mef2) activation in myocytes predicts focal scarring in hypertrophic cardiomyopathy. Proc Natl Acad Sci USA 2010; 107: 18097-18102.

26. Kim JB, Porreca GJ, Song L, Greenway SC, Gorham JM, Church GM, et al. Polony multiplex analysis of gene expression (PMAGE) in mouse hypertrophic cardiomyopathy. Science 2007; 316: $1481-1484$.

27. Rodrigues JC, Rohan S, Ghosh Dastidar A, Harries I, Lawton $\mathrm{CB}$, Ratcliffe LE, et al. Hypertensive heart disease versus hypertrophic cardiomyopathy: Multi-parametric cardiovascular magnetic resonance discriminators when end-diastolic wall thickness $>/=15 \mathrm{~mm}$. Eur Radiol 2017; 27: 1125-1135.

28. Kim Y, Phan D, van Rooij E, Wang DZ, McAnally J, Qi X, et al. The MEF2D transcription factor mediates stress-dependent cardiac remodeling in mice. $J$ Clin Invest 2008; 118: 124-132.

29. Galati G, Leone O, Pasquale F, Olivotto I, Biagini E, Grigioni $\mathrm{F}$, et al. Histological and histometric characterization of myocardial fibrosis in end-stage hypertrophic cardiomyopathy: A clinical-pathological study of 30 explanted hearts. Circ Heart Fail 2016; 9: e003090.

30. Hen Y, Iguchi N, Utanohara Y, Takada K, Machida H, Takara A, et al. Extent of late gadolinium enhancement on cardiac magnetic resonance imaging in Japanese hypertrophic cardiomyopathy patients. Circ $J$ 2016; 80: 950-957.

31. Konno T, Hayashi K, Fujino N, Oka R, Nomura A, Nagata Y, et al. Electrocardiographic QRS fragmentation as a marker for myocardial fibrosis in hypertrophic cardiomyopathy. J Cardiovasc Electrophysiol 2015; 26: $1081-1087$

32. Maron MS, Rowin EJ. The role of cardiac MRI in the diagnosis and risk stratification of hypertrophic cardiomyopathy. Arrhythm Electrophysiol Rev 2016; 5: 197-202.

33. Fujita T, Fujino N, Anan R, Tei C, Kubo T, Doi Y, et al. Sarcomere gene mutations are associated with increased cardiovascular events in left ventricular hypertrophy: Results from multicenter registration in Japan. JACC Heart Fail 2013; 1: 459-466.

34. Olivotto I, Girolami F, Ackerman MJ, Nistri S, Bos JM, Zachara $\mathrm{E}$, et al. Myofilament protein gene mutation screening and outcome of patients with hypertrophic cardiomyopathy. Mayo Clin 
Proc 2008; 83: 630-638.

35. Kramer CM, Appelbaum E, Desai MY, Desvigne-Nickens P, DiMarco JP, Friedrich MG, et al. Hypertrophic Cardiomyopathy Registry: The rationale and design of an international, observational study of hypertrophic cardiomyopathy. Am Heart J 2015; 170: $223-230$.

36. Anan R, Niimura H, Takenaka T, Hamasaki S, Tei C. Mutations in the genes for sarcomeric proteins in Japanese patients with onset sporadic hypertrophic cardiomyopathy after age 40 years. Am J Cardiol 2007; 99: 1750-1754.

37. Yamauchi-Takihara K, Nakajima-Taniguchi C, Matsui H, Fujio Y, Kunisada K, Nagata S, et al. Clinical implications of hypertrophic cardiomyopathy associated with mutations in the alphatropomyosin gene. Heart 1996; 76: 63-65.

38. Matsushita Y, Furukawa T, Kasanuki H, Nishibatake M, Kurihara Y, Ikeda A, et al. Mutation of junctophilin type 2 associated with hypertrophic cardiomyopathy. J Hum Genet 2007; 52: 543-548.

39. Ingles J, Doolan A, Chiu C, Seidman J, Seidman C, Semsarian C. Compound and double mutations in patients with hypertrophic cardiomyopathy: Implications for genetic testing and counselling. J Med Genet 2005; 42: e59.

40. Watkins H, McKenna WJ, Thierfelder L, Suk HJ, Anan R, O'Donoghue A, et al. Mutations in the genes for cardiac tropo$\operatorname{nin} \mathrm{T}$ and alpha-tropomyosin in hypertrophic cardiomyopathy. N Engl J Med 1995; 332: 1058-1064.

41. Watkins H, Rosenzweig A, Hwang DS, Levi T, McKenna W, Seidman CE, et al. Characteristics and prognostic implications of myosin missense mutations in familial hypertrophic cardiomyopathy. $N$ Engl J Med 1992; 326: 1108-1114.

42. Bos JM, Will ML, Gersh BJ, Kruisselbrink TM, Ommen SR, Ackerman MJ. Characterization of a phenotype-based genetic test prediction score for unrelated patients with hypertrophic cardiomyopathy. Mayo Clin Proc 2014; 89: 727-737.

43. Erdmann J, Daehmlow S, Wischke S, Senyuva M, Werner U, Raible J, et al. Mutation spectrum in a large cohort of unrelated consecutive patients with hypertrophic cardiomyopathy. Clin Genet 2003; 64: 339-349.

44. Nishi H, Kimura A, Harada H, Adachi K, Koga Y, Sasazuki T, et al. Possible gene dose effect of a mutant cardiac beta-myosin heavy chain gene on the clinical expression of familial hypertrophic cardiomyopathy. Biochem Biophys Res Commun 1994; 200: $549-556$.

45. Christiaans I, Birnie E, van Langen IM, van Spaendonck-Zwarts KY, van Tintelen JP, van den Berg MP, et al. The yield of risk stratification for sudden cardiac death in hypertrophic cardiomyopathy myosin-binding protein $\mathrm{C}$ gene mutation carriers: Focus on predictive screening. Eur Heart J 2010; 31: 842-848.

46. Harris SP, Lyons RG, Bezold KL. In the thick of it: HCMcausing mutations in myosin binding proteins of the thick filament. Circ Res 2011; 108: 751-764.

\section{Supplementary Files}

\section{Supplementary File 1}

Figure S1. Clinical and genetic profiles of a representative case with HCM.

Figure S2. Scatterplots of intra- and interobserver variations for $\%$ LGE measurements.

Table S1. The 21 genes comprising the original panel and 174 genes comprising the TruSight Cardio panel

Please find supplementary file(s);

http://dx.doi.org/10.1253/circj.CJ-17-1012 